El Profesor Remy Amador Presas (19 DE DICIEMBRE DE 1936 28 DE AGOSTO DE 2001).

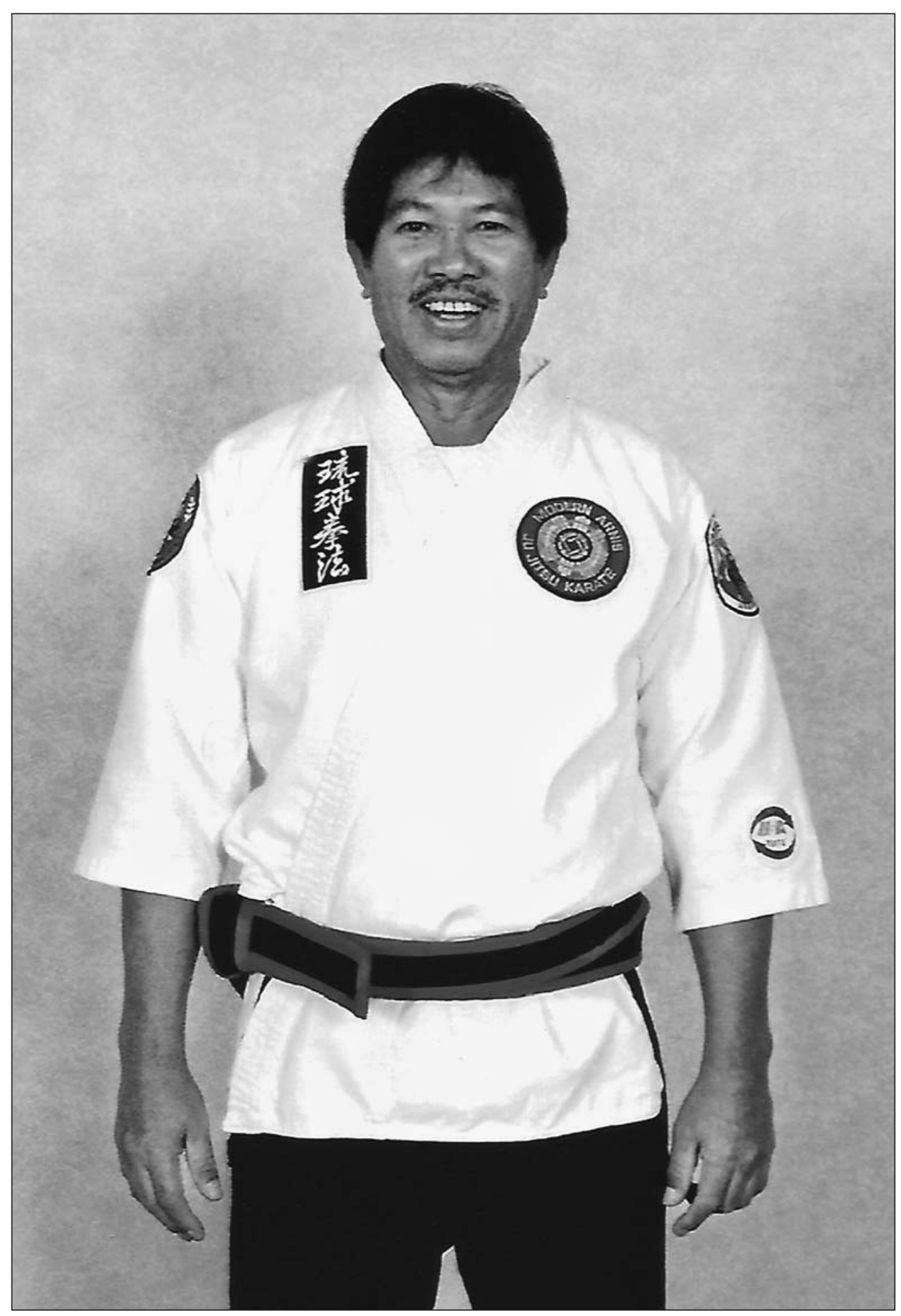

\title{
Resumen
}

El Profesor Remy Presas fue el fundador de un estilo marcial llamado Arnis Moderno. Trajo este conocimiento y sus propias innovaciones a los EE.UU. y al resto del mundo, comenzando a mediados de los años $70, y$ fue uno de los cuatro maestros que formaron alianza, compartiendo ideas y estudiantes a lo largo de las siguientes décadas. El Profesor Presas murió antes de ser entrevistado para la serie de reportajes que venimos publicando, por lo que esta retrospectiva comprende las historias y recuerdos de muchos de los que le conocieron y amaron. 


\title{
Recordando a Remy Presas UNA PERSPECTIVA VITAL EN
}

\section{LAS ARTES MARCIALES}

\author{
Peter Hobart
}

STS

\section{Introducción}

Durante los años 80, una década que encarnó la primacía de los intereses individuales a muchos niveles, ocurrió algo verdaderamente notorio en la comunidad norteamericana de las artes marciales. En medio de la feroz competencia entre los distintos estilos, escuelas y organizaciones, un grupo de grandes maestros -todos reconocidos expertos e innovadores en sus particulares disciplinas- se agruparon para compartir ideas, técnicas y seminarios prácticos con los demás. El resultado fue que sus estudiantes de todo el mundo disfrutaron de una amplitud y profundidad de instrucción incomparable en la experiencia ordinaria. Las antiguas artes de lucha de Japón, China, Okinawa y las Filipinas mezcladas conjuntamente a modo de coro que conservaba la cualidad distintiva de cada voz, pero que se combinaban para producir una armonía de cuatro partes cuya fuerza realmente excedía la suma individual.

Como una de esas personas lo suficiente afortunada como para presenciar este fenómeno, decidí hace mucho tiempo entrevistar a cada uno de los destacados miembros de esta extraordinaria unión, con el fin de comparar sus pensamientos y experiencias en diversos temas. Para mi gran vergüenza, no pude llevar a cabo esta buena intención antes de que ocurriese lo inconcebible. Uno de los miembros fundadores, el Profesor Remy Amador Presas, murió de forma inesperada, y el círculo se rompió para siempre.

Hace muchos años se realizó un seminario de fin de semana en Filadelfia al que el Profesor Presas llegó días antes. Fui honrado con el cometido de acompañarle por los alrededores en el ínterin, teniendo la oportunidad de hablar, entrenar, y comer con él cara a cara. Todavía recuerdo vívidamente muchas de las cosas que discutimos y practicamos, pero otras comienzan a desvanecerse con el tiempo. Sólo después de haber completado las demás entrevistas que me había comprometido realizar tiempo atrás, parecía que era el momento correcto para poner por escrito las palabras del Profesor Presas que aún estaban disponibles en viejos fragmentos de cintas de video, notas manuscritas, memorias borrosas y la amable asistencia de aquellos que contribuyeron con sus propias historias en este proyecto.

Todas las fotografías son cortesía de Peter Hobart. 


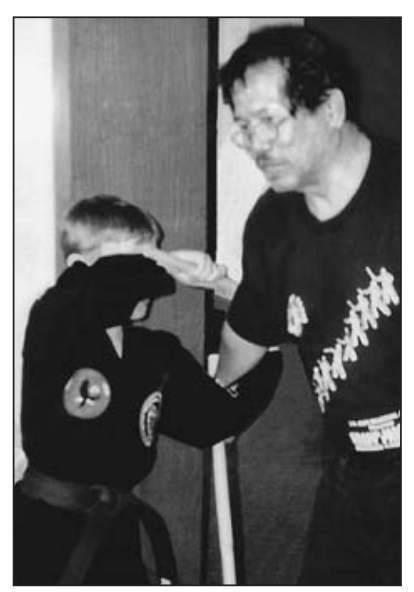

El Profesor Presas enseñó

A PERSONAS DE TODA EDAD Y EXPERIENCIA. AQUí, Un JOVEN PRACTICANTE UTILIZA SU BASTÓN PARA BLOQUEAR EL CODO DEL Profesor Presas.

\section{TEMAS}

\section{- Sobre ser un maestro:}

El asunto con el que el Profesor parecía más preocupado en los días previos al seminario antes citado era lo que él llamaba "presentación" o "perfil." Algunas personas consideran que la habilidad de inspirar e implicar a los otros es una herramienta útil si se desea ser maestro. Al oír decírselo al Profesor éstos se echaban atrás. A él le parecía que sólo por tener tales dones naturales ya se les exigía a sus dueños que enseñaran a otros -se supone que cualquier materia, pero, en especial, Arnis.

"Algunas personas", explicó, "tienen don, perfil natural,... deben enseñarlo".

\section{- Referente al fluir:}

La otra cosa que parecía ser lo más importante en la mente del Profesor, durante la ocasión descrita arriba, era el ejercicio conocido como "tapi-tapi". Le recogí en su hotel, y antes de que entrase a su cuarto me dio un bastón de Arnis y dijo, "golpéeme aquí con el pamalo (bastón)". Insospechadamente, accedí. La siguiente cosa que percibí fue un ciclón de actividad del Profesor y me encontré desarmado, con mis antebrazos enredados el uno con el otro, y él riéndose de oreja a oreja. "QQué fue eso?", pregunté. "Le llamamos tapitapi”, contestó. "Te lo explicaré más a fondo, pero primero ¡vamos a comer!"

De camino al dojo, el Profesor rechazó varias opciones de comida rápida, optando en su lugar por un viaje al pasillo de productos de la tienda de ultramarinos local. Media hora más tarde, armado con diversas frutas frescas y una daga de artes marciales, nos hizo una de las mejores ensaladas de frutas que he saboreado y que comimos juntos, sentados con las piernas cruzadas en el suelo del dojo.

Después, la lección continuó. Como una ola gigantesca, la técnica del Profesor surgía contra mis ineficaces defensas, haciéndome ir y venir a lo largo y ancho del dojo. La "innovación del tapi-tapi" se mezclaba fluidamente con algunos de los ejercicios más tradicionales y familiares. Él seguía un ataque para contraatacar y desarmar, tan rápida y fluidamente que estaba claro que era una aplicación instintiva de la técnica y no una aplicación consciente. Cuando terminó la lección, el Profesor sonrió ampliamente y dijo, "esto es el fluir". En aquel momento pensé que se refería a los propios movimientos. Hoy, tras muchos años, creo que comienzo a entender su significado.

BLOQUEO DE MUÑECA Y ESTRANGULACIÓN: DOS TÉCNICAS DE FINALIZACIÓN UTILIZADAS DESPUÉS DEL INTERCAMBIO DE MÚLTIPLES GOLPES Y ESQUIVAS EN EL ENTRENAMIENTO “TAPI-TAPI” DE DOS PERSONAS,
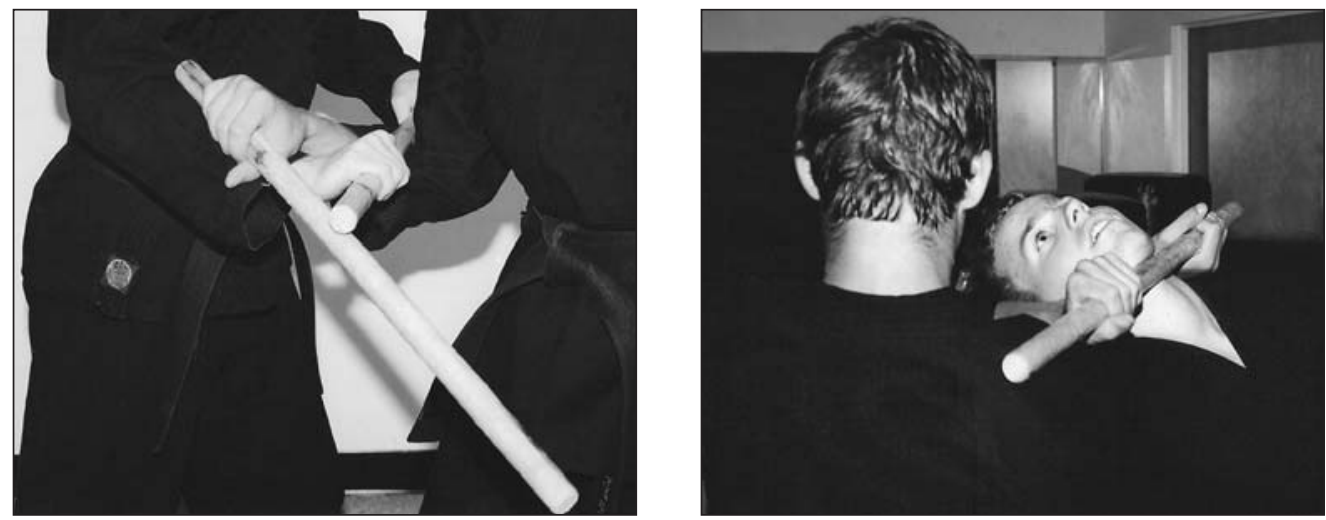


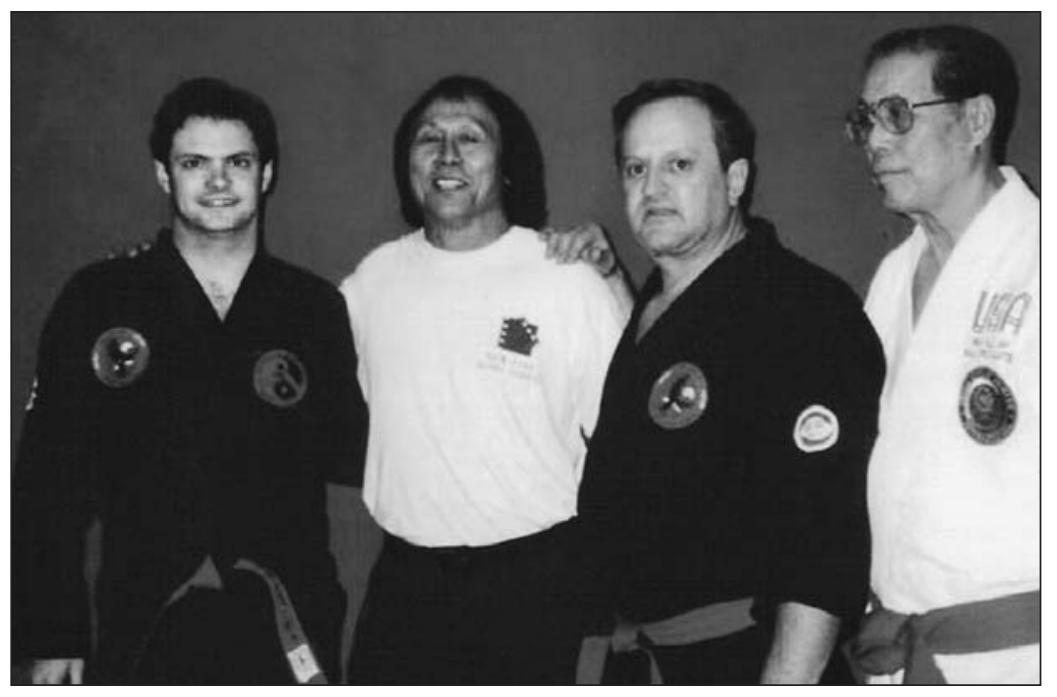

DE IZQUIERDA

A DERECHA: EL

Dr. Charles

TERry, GEORGE

Dillman, LeO

FONG Y WALLY

JAY, ALLÁ POR EL AÑo 1997.

- Según las palabras de sus colegas:

WALLY JAY: "Cuando Remy enseñaba, algunas veces podía meterme en sus clases, pero no conocía su arte. Si yo se lo demostraba a un alumno Remy me diría: "Las conoces, conoces las artes. Es el principio lo que es importante".

GEORGE DILLMAN: "Remy, le echo de menos con tristeza. Siempre digo a la gente que era mi agente. Remy podía llamarme: "Tu y yo impartiremos un seminario. Lo haremos en Atlanta, Georgia”. Yo preguntaba: “impartiremos?". Y decía: "Si, si, debes estar allî” ¡Y después colgaba! Y hacía lo mismo con Wally, y nos ponía a los tres juntos, y esto fue tremendo, durante casi quince años.

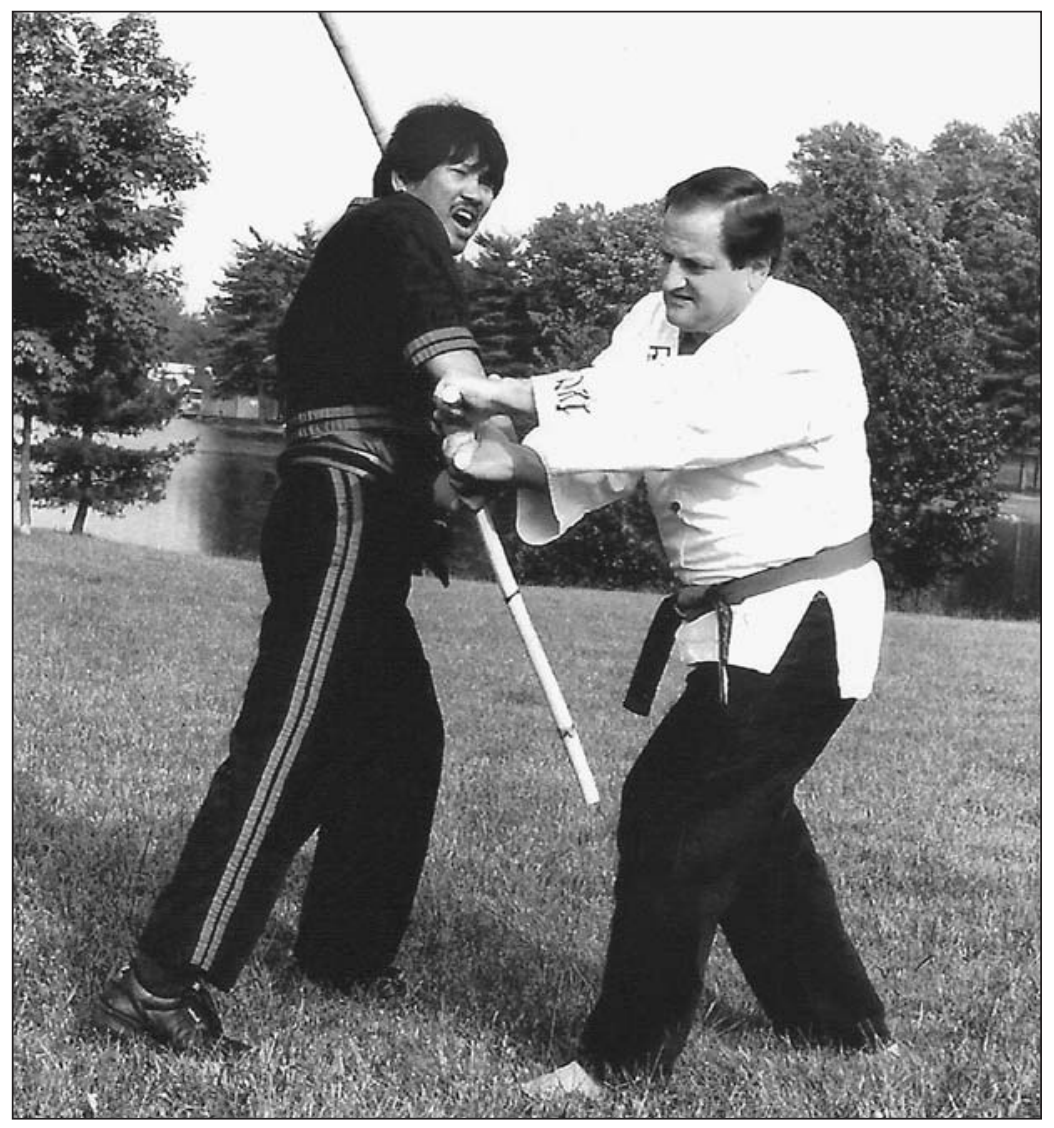

El Profesor

Presas y George

Dillman

PRACTICANDO

TÉCNICAS DEL

ARnis MOdERno.

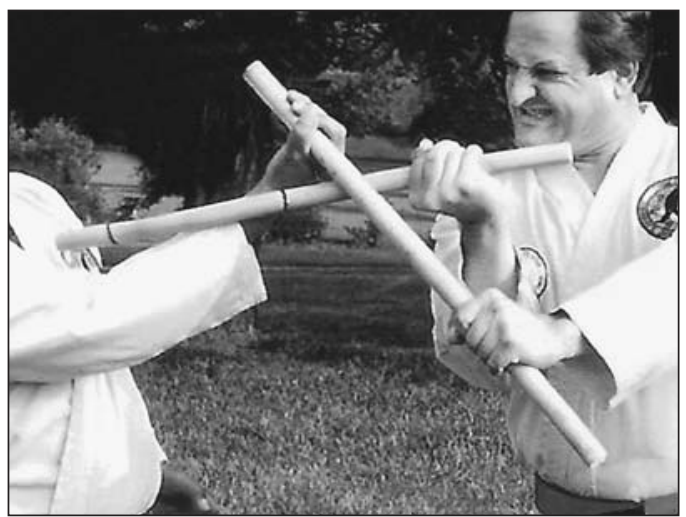


LEO FONG: "Me entrené con Remy durante un año en 1974, cuando estaba en las Filipinas para hacer dos películas. Viví allí durante un año entero. Remy aparecía en mi apartamento cada mañana a las 7:00. Algunas veces estaba en la cama cuando llamaba a la puerta. Nos entrenábamos durante una hora, y algunas veces pasábamos el día juntos dando paseos en taxi y jeep, yendo a diferentes lugares como cafés y estudios de cine. En lo que concierne a las artes marciales, aprendí cosas acerca del fluir y de lograr una aproximación integral. Remy no trabajaba solamente las armas, sino el espectro completo de las artes marciales. Aunque mi preferencia personal es desarrollar y diseñar mi propio método, el observar a Remy me inspiró a salir "fuera del cajón”. Es por esto que no enseño las técnicas específicas de todos los maestros con quienes me entrené, como Remy, Angel Cabales, Bruce Lee, Jimmy Lee, etc. Un gran maestro es el que señala la puerta con el dedo, pero no entra con el estudiante. He tenido suerte de encontrar a Remy y a otros que fueron grandes maestros por esta razón. Me enseñaron a pescar en vez de simplemente darme un pez. Durante el proceso también descubrí el "cómo" por mí mismo. Recuerdo a Remy como una persona muy generosa que estaba ansiosa por compartir su arte. El mismo día en que lo conocí bullía de entusiasmo. La primera cosa que me preguntó después de una pequeña presentación fue: ‘Cuándo podemos iniciar el entrenamiento?"'.

DR. CHARLES TERRY: "Fui muy afortunado al poder ir varios años a seminarios y campamentos del Profesor Presas. Valoro especialmente los meses que pasamos juntos viajando a los seminarios después de que acabé la escuela de medicina. Un aspecto de su carácter se quedará siempre conmigo: al Profesor Presas le encantaba compartir. Ccompartió técnicas y conceptos con artistas marciales de todo tipo y nivel. Parte de lo que ha hecho que el Arnis Moderno se haya difundido tanto fue la sinceridad del Profesor con todos los estudiantes. Trató a los principiantes y a los estudiantes avanzados con igual atención y respeto. El Profesor tenía un interés personal en todo aquel que se encontraba. Para él era importante recordar los nombres y las caras de la gente. Conoció a mi familia y siempre preguntaba por su salud y felicidad. Fue una de las primeras personas en enviarme un regalo de boda cuando le dije que estaba comprometido. Una vez que estábamos

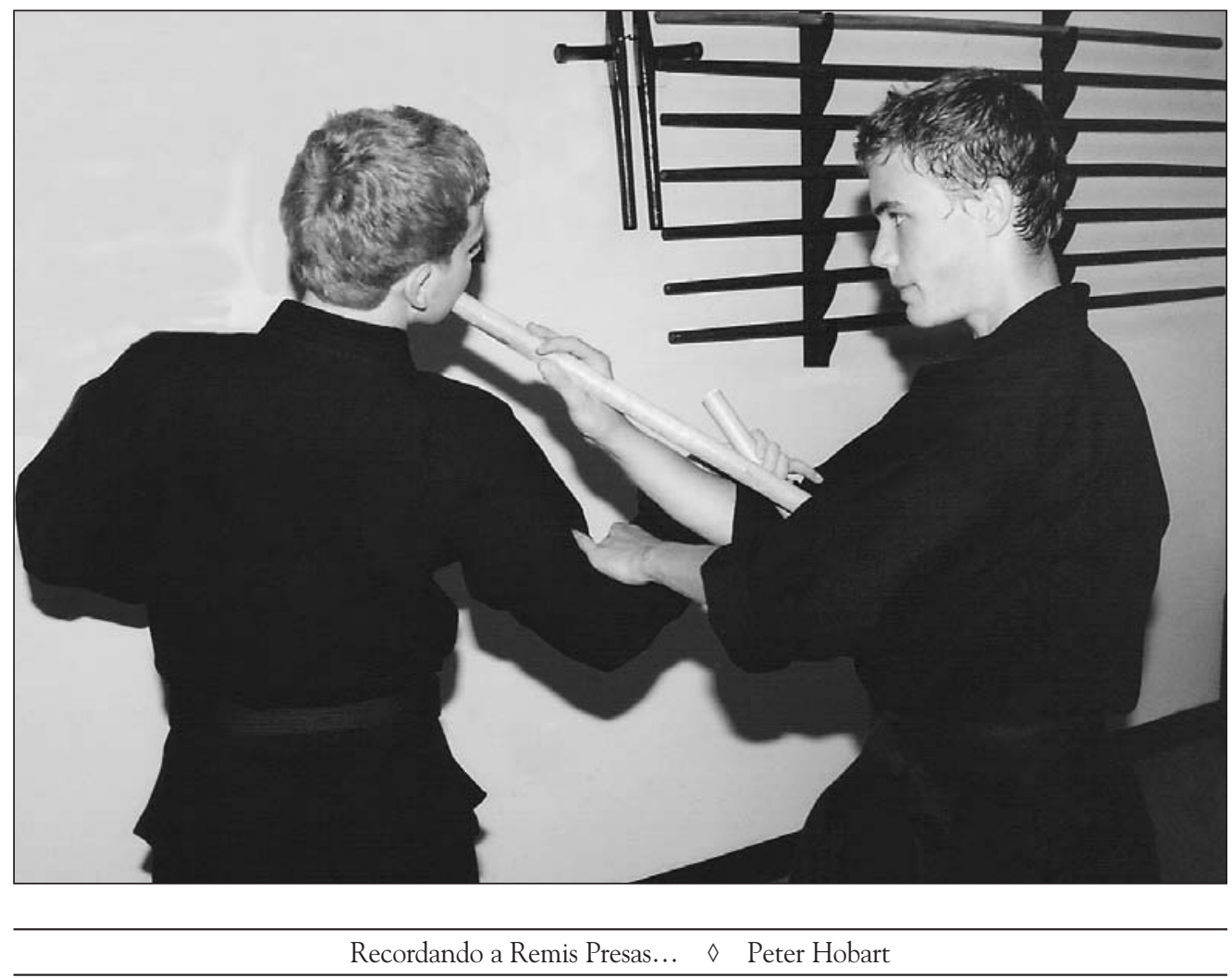


en carretera, le pregunté dónde podría obtener uno de los uniformes especiales de Arnis Moderno. Rápidamente, él se quitó la parte superior de su uniforme y dijo, "Doctor Terry, quiero que tenga esto”. ¡Literalmente se quitó su camisa para dármela!”.

CHAD DULIN: "Pienso que muchos observadores no se dieron cuenta de que Remy te podía conocer tan a fondo que sabía, con certeza, lo que ibas a hacer antes de que lo hicieses. Y cuando quería que hicieses algo, no sólo sabía cómo hacer que lo realizases, sino también cómo hacer que lo quisieses hacer, comprometiéndote a hacerlo y pensando que ibas a hacer algo bueno. Es lo que a tantos les falta hoy en día. Se oye demasiadas veces, "no puedes hacer eso; eso no está en el entrenamiento". Esto es erróneo desde mi punto mi vista. Remy nunca decía: "no puedes hacer eso". Siempre tuvo una respuesta para el movimiento no previsto, pero, mucho más importante, raramente obtenía movimientos inesperados. Obtenía las respuestas que buscaba mediante cálculos muy cuidadosos y llevándolas a cabo.

Remy poseía algunas cualidades realmente portentosas: un asombroso agarre, una mecánica corporal de excelente calidad, y la sincronización de la habilidad para prever e imponerse a un adversario. Ralentizaba los movimientos de muchas formas, pero también cambiaba la estructura de éstos para simplificar su seguimiento y aprendizaje. Por ejemplo, ralentizaría las cosas mucho más de lo necesario para que la gente las pudiese ver, pero también aislaba otras como el juego de pies. Algunos observadores han comentado que el Arnis Moderno parece carecer del juego de pies triangular característico de las artes marciales filipinas. Claramente, este no es el caso, es simplemente que Remy raramente se movía más de lo necesario, y podía hacerlo, y hacía correr a contrincantes mas grandes y fuertes que él por toda la estancia usando estos pasos casi de niño pequeño.

Pero creo que el éxito de Remy, realmente, dependió de una sola cualidad. Podía hacer que hasta la última persona de un seminario se sintiese como el centro de todo. Se aseguraba de que nadie se quedase atrás, y se aseguraba de que toda persona percibiera parte de la alegría que él mostraba cuando enseñaba. Todo el mundo se iba con algo que no tenía cuando llegó, ya fuesen debutantes o llevasen veinte años practicando".

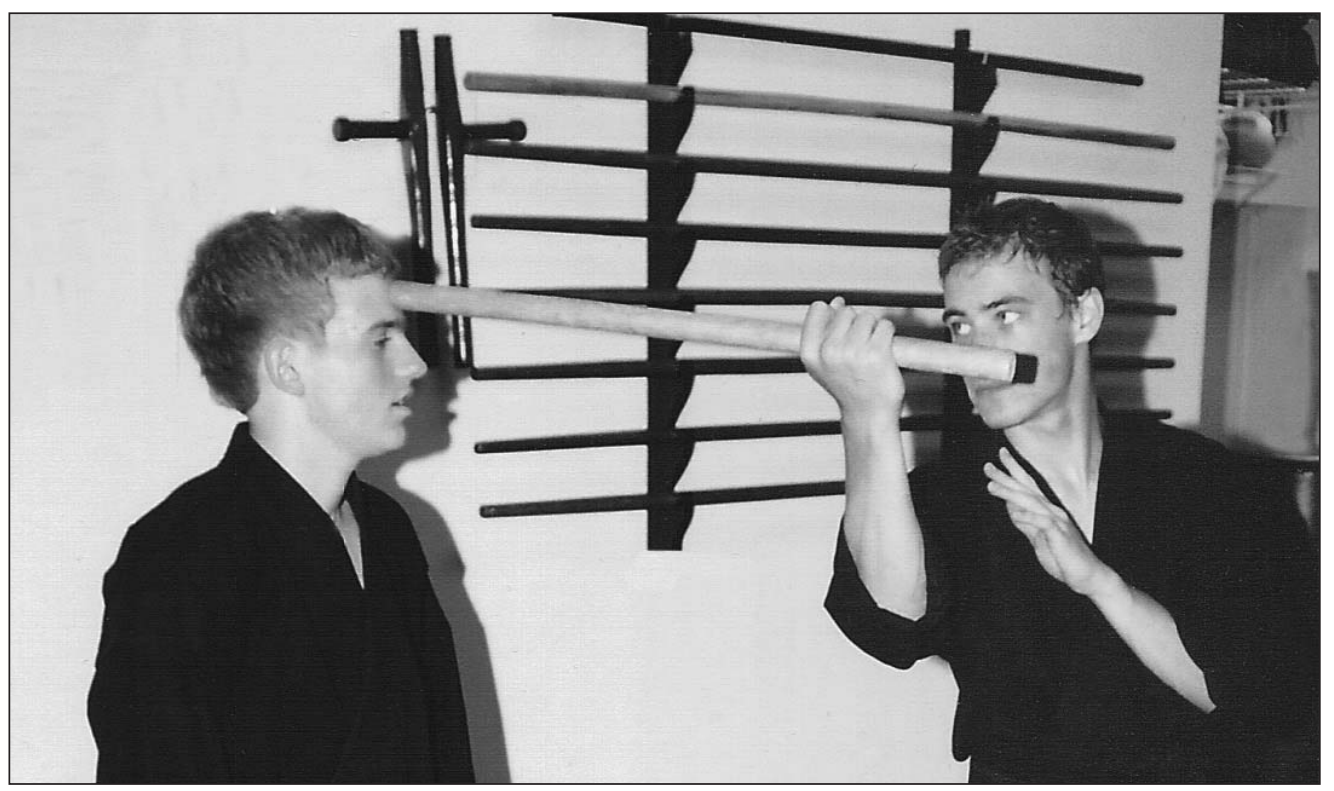

PÁGINA PREVIA:

JaKe ECKHARDT y DAVID KeRKESLAger PRACTICAN EL GOLPEO CON EL PUNYO.
ARRIBA:

EJECUTANDO UN GOLPE BÁSICO A LA FRENTE O AL OJO.

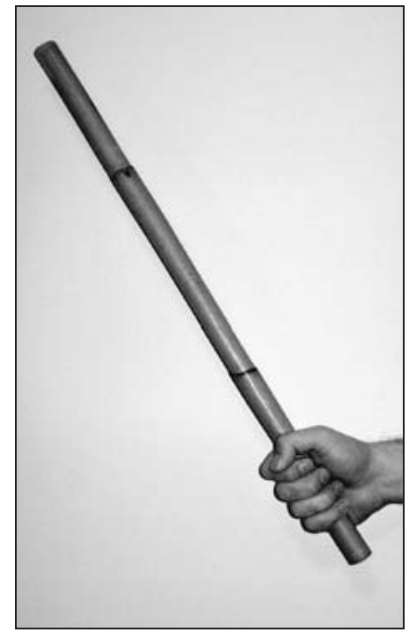

ARRIBA:

LA FORMA CORRECTA DE AGARRAR EL BASTÓN ARNIS, CON EL SUFICIENTE PUNYO POR DEBAJO DEL AGARRE PARA GOLPEAR O ENGANCHAR. 
"El BloQueo Del PARAGUAS": UNA DEFENSA PARA EVITAR UN GOLPE EN LA CABEZA.

SINAWALI INVERSO (LA TRAMA): UNA TÉCNICA DE DOS PERSONAS EN LA QUE CADA UNO DE LOS DIVERSOS GOLPEOS SE ENCUENTRA CON

UN CONTRAGOLPE IGUAL REALIZADO POR EL COMPAÑERO.

REDONDA (EL CICLÓN): UNA TÉCNICA PARA PRACTICAR UN FLUJO CONTINUO DE GOLPES.
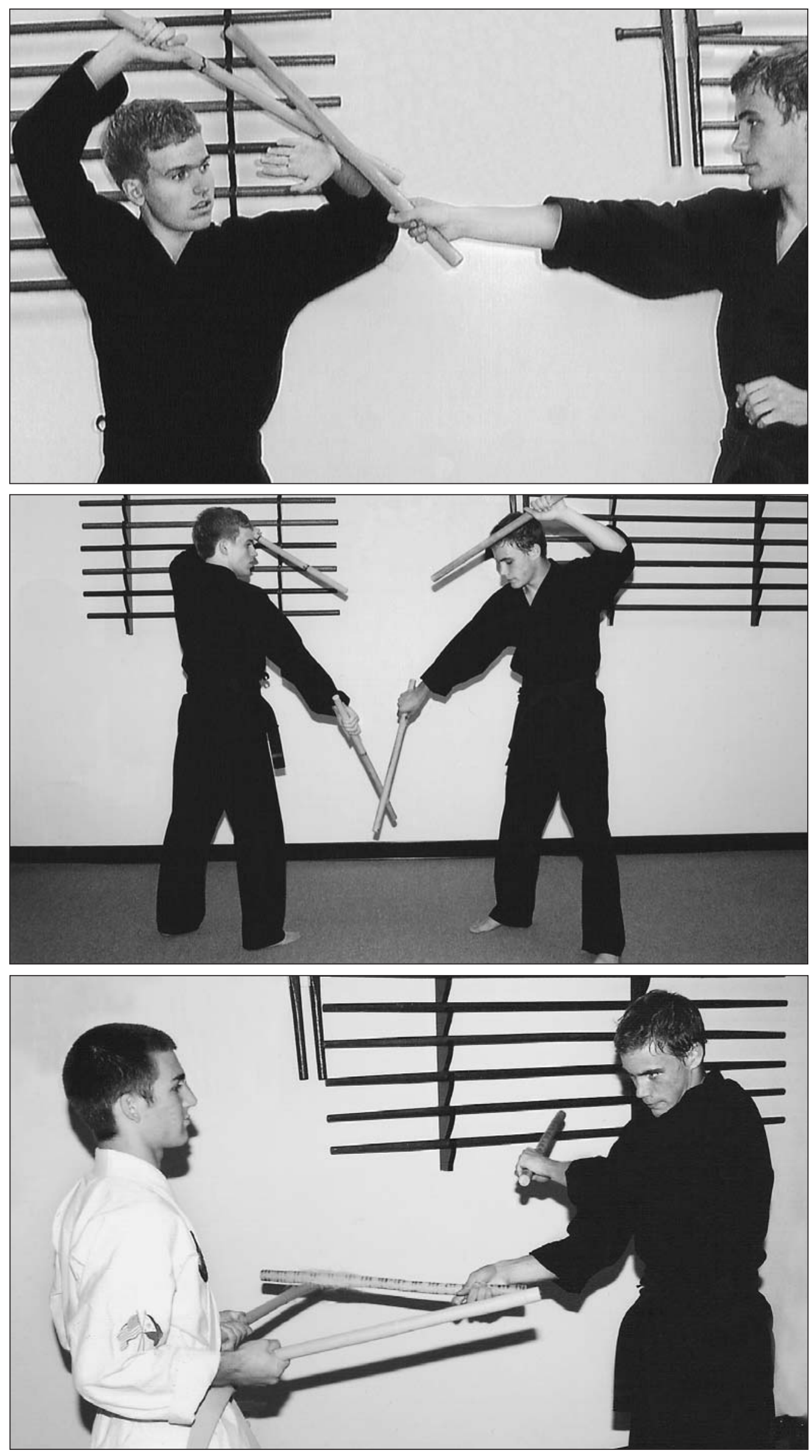

Recordando a Remis Presas... $\diamond$ Peter Hobart 


\section{- Su sentido del humor:}

En 1996 se realizó un campamento intensivo de Arnis de cuatro días en un colegio mayor de un campus de Nueva Inglaterra. Hacía calor y el entrenamiento era riguroso. En una sesión a última hora de la tarde, el bastón de mi compañero se resbaló con el sudor, suavemente, y golpeó mis nudillos. Por un momento, mi mano se entumeció, haciendo que la punta de mi bastón cayese hacia abajo bruscamente, llegando a descansar al lado de la ingle de mi compañero.

Al día siguiente en el desayuno, el Profesor Presas advirtió el vendaje de mi dedo. "¿Qué sucedió?", preguntó con verdadera preocupación. "Chris me golpeó en el dedo", contesté, dirigiendo la cabeza hacia mi amigo. "En justicia", Chris añadió, "Peter me golpeó luego en la ingle". El Profesor reflexionó sobre esto durante un momento, y luego dijo a Chris con una sonrisa burlona: "En ese caso, usted pierde."

\section{- Su último seminario importante:}

En febrero de 2001 se realizó una reunión intensiva de Arnis de fin de semana en Filadelfia. Durante el primer día, los estudiantes, que habían venido de todas partes, estaban desilusionados al ver que parecía que el Profesor, que recientemente había caído enfermo, sería incapaz de asistir. No obstante, se entrenaron duro bajo la atenta mirada de los estudiantes de último año, y aprendieron gran cantidad de cosas. En la tarde del segundo día, cuando el aire era denso, con olor a madera humeante y con el estrépito de los bastones, se produjo un revuelo en las proximidades del vestíbulo.

Cuidadosamente, el Profesor, habiéndose escapado de hospital y mostrando aún señales recientes de cirugía, se abrió paso en el local y examinó a la sonriente multitud que le daba la bienvenida. Todo movimiento se detuvo. Uno por uno, dio la bienvenida a cada rostro familiar. Cuando se acercó a mí pareció examinarme, y simplemente murmuró, "Hola Steve". Yo estaba acongojado, pero le sonreí, y dije, "Hola Profesor".

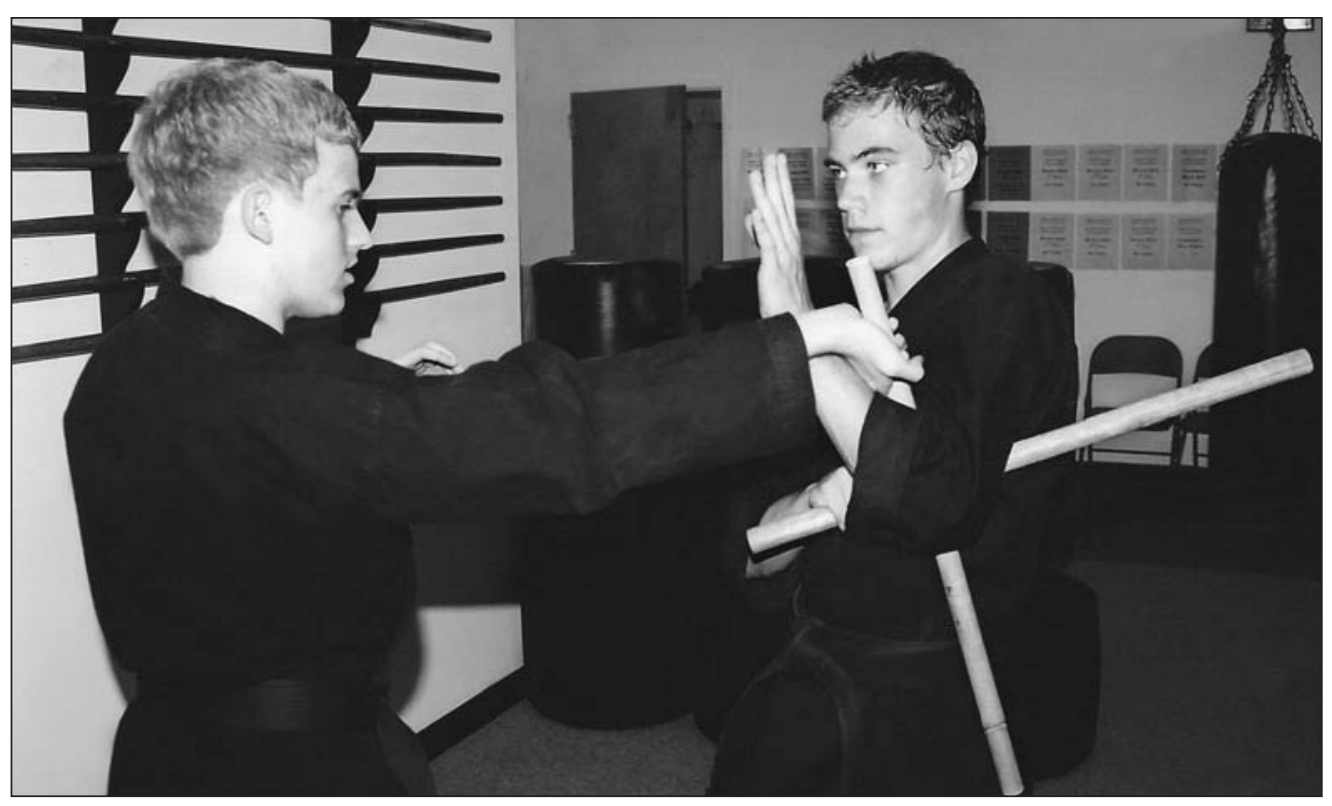

BLOQUEO-CONTROL-

CONTRAATAQUE: ESQUIVAR Y CONTRAR.

Después DE BLOQUEAR UN GOLPE DESCENDENTE, EL DEFENSOR CONTINÚA CON UNA TÉCNICA DE DESARME. 


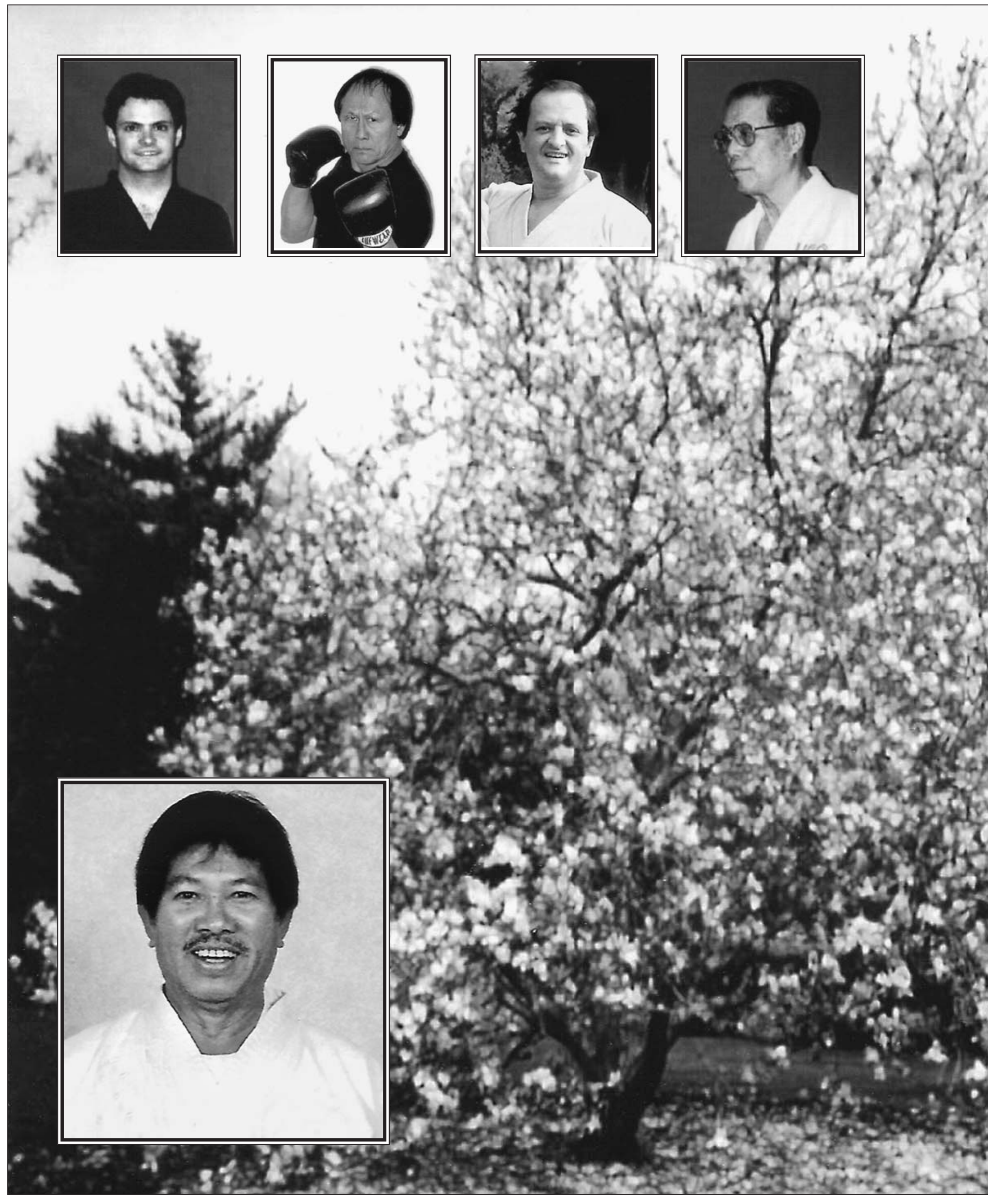




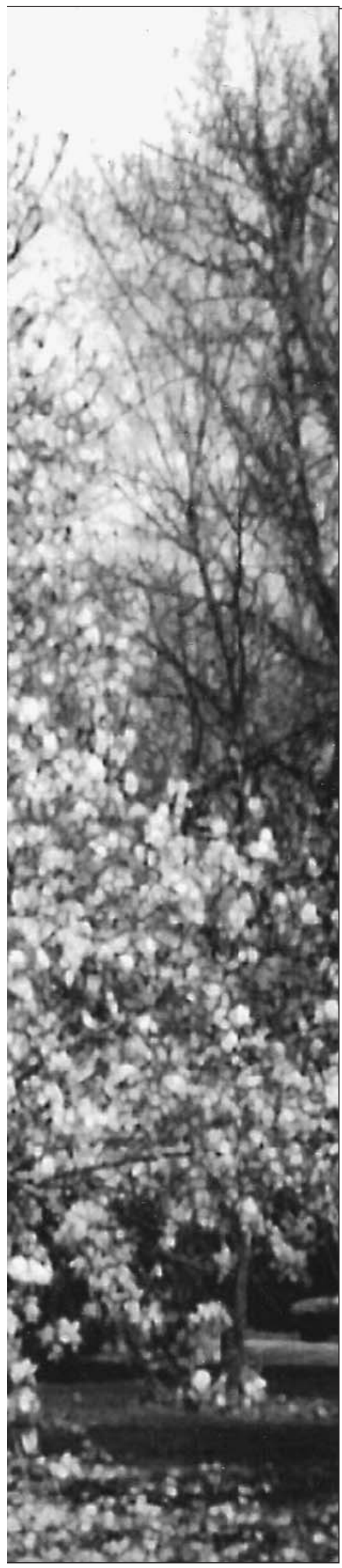

Pasado el momento se reanudó el entrenamiento, y el Profesor fue acompañado a una silla a un lado de la sala. Después de algunos minutos, el entrenamiento se paró de nuevo repentinamente, esta vez tras una sonora voz del Profesor: “¡Peter!”. Miré, sin saber cómo reaccionar. Algunos de los estudiantes de último año que estaban rodeándole me llamaron por señas. Cuando me acerqué a él, tomó mi mano y dijo, "Lo siento, no te reconocí. Mi vista no está en su mejor momento". Aún en esta crítica condición, para él era importante asegurarse de no dañar mis sentimientos. Esta era, simplemente, la clase de caballero que fue.

\section{- Una imagen:}

Como todos sus estudiantes sabían, el Profesor era un hombre de pocas palabras, honrando el aforismo de las artes marciales de "haz, no hables". En consecuencia, una retrospectiva escrita apenas puede hacer justicia a su memoria. Las imágenes que siempre recordaremos: la sonrisa, ancha sincera, del Profesor; el brillo de sus ojos cuando contaba un chiste, o su simple sentimiento de felicidad. En ocasiones más serias "haciendo el mano" -el símbolo filipino de respeto que se ejecuta colocando el anverso de la mano en la frente-. Esto habla con mayor elocuencia del encanto y carácter de un hombre de lo que lo que pueden transmitir las palabras.

\section{- Dedicar tiempo a oler las rosas:}

Mientras era conducido hacia el seminario citado al principio de este artículo, el Profesor exclamó repentinamente: “iDetenga el coche!”. Preocupado porque quizá se sintiese mal, obedecí inmediatamente. El coche derrapó hasta pararse en el arcén, levantando grava y polvo y haciendo que algunos conductores tocasen la bocina airadamente. Después de que hubiésemos parado el Profesor saltó fuera y retrocedió unas cien yardas, parándose al borde de un prado.

Tras un momento le seguí para ver cuál era el problema. Al acercarme, estuvo claro qué era lo que cautivaba su atención. En mitad del campo había un cerezo en flor, solitario, resplandeciente. Pasó un minuto en silencio. Luego el Profesor dijo, "es bello", y corrió de regreso al coche como si no hubiese sucedido nada en particular. Quizá, para él, nada sucedió.

\section{- Los últimos días:}

Pocos días antes de que muriese, el Profesor llamó a mi casa en Harrisburg desde el hospital de Victoria, queriendo hablarnos a mi esposa y a mí. Durante cerca de media hora, charlamos acerca de esto y lo otro, de nada importante. Parecía lúcido y feliz, pero al final, en nuestra última conversación, nos dijo, "os quiero, lo sabéis"

Nosotros también le queremos, Profesor, le echamos de menos, y esperamos que dondequiera que esté, haya al menos algunos cerezos.

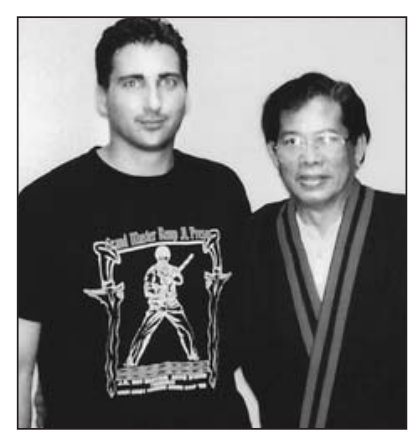

El autor con el Profesor PRESAS EN UN SEMINARIO DIRIGIDO EN LA UNIVERSIDAD de Pensilvania, Cerca de 1995. 